\title{
A Study of Demotivators in Chinese University's English as a Foreign Language Teaching and Learning
}

\author{
Guimei Xie \\ School of Foreign Languages and Cultures, Beijing Wuzi University, Beijing, China
}

Email address:

guimeixie@126.com

\section{To cite this article:}

Guimei Xie. A Study of Demotivators in Chinese University's English as a Foreign Language Teaching and Learning. Higher Education Research. Vol. 5, No. 4, 2020, pp. 143-153. doi: 10.11648/j.her.20200504.15

Received: May 23, 2020; Accepted: June 15, 2020; Published: June 28, 2020

\begin{abstract}
Demotivation and motivation study among foreign language learning has been salient and meaningful around the world since they influence the result of language performance. Different demotivators were drawn by different researchers coming from different perspectives. The objective of this paper is to investigate and develop demotivating factors in a Chinese foreign language learning context and explore the implications of these factors on future teaching. This study investigated 588 college students from a Beijing municipal university in a survey on demotivating items which influenced their foreign language learning considering their past personal language study experience. The methodology of the study is both qualitative and quantitative. The key findings of the study were that 7 Demotivators were distracted by using SPSS: teacher-related competence factor, learner-level factor, teaching content and material, inadequate school facilities and judgement, grammar-translation teaching method, confuse of purpose of language study, and testing and grading system. All the factors, especially the teacher-related demotivating factor, were identical with most research findings. While students-related factors were prominent factors in the study. This research is valuable for both secondary and high school teachers as it demonstrates students' demotivating and negative factors in drawing students back in the process of language study and improves pedagogical means and methods by bridging the gap between researchers and educational practitioners. It can also inform educational bureau and families in the society about this current trend and how it could influence the students' foreign language learning process.
\end{abstract}

Keywords: Demotivation, Demotivator, Factor, EFL Instruction

\section{Introduction}

Problems of demotivation in SLA have constantly and harassingly been one of the hot research topics among researchers around the world. Demotivation, as the dark side of motivation study since Gardner and Lambert explored the field [1], has been one of the issues confronting both teachers and researchers. As one of the most popular universal languages at present and even become global English [2], English study is also facing a downside situation since some learners feel too much frustration in the constant long-time endeavor of study and even fail some exams at the end. Demotivation is becoming a salient phenomenon and recurring topic in L2 studies and a few significant research studies were concerned about demotivation in the field of foreign language context or L2 context in the past few decades [2-15].

Demotivation was firstly defined as 'specific external forces that reduce or diminish the motivational basis of a behavioral intention or an ongoing action' [6]. Study of demotivation originated from the United States and UK. In the United States, surveys were conducted in content courses like instructional communication and introductory communication course in college lecture classes with the focus of teacher misbehaviors as demotivators where causes of demotivation among college students were teacher-owned in qualitative investigations [16-18]. The issue spread to the field of foreign language study and flourished qualitatively and quantitatively worldwide in places like Japan [3, 4, 9, 11, 19], Korea [10, 20], UK [21], Hungary [6], China [13]-15], and even Malaysian Arabic learners [22] in foreign language study and second language study from elementary school students [20], middle school students [4-6] to college and university students of English major and non-English major [3, 11].

This study, based on the recent research studies from different social contexts in Japan, Korea, Hungary and China, 
developed a study on college students' demotivation in Beijing, capital of China. It investigated the demotivators among college students' English as a foreign language study and in what extent do these factors overlap with students in other countries?

EFL instruction in China's colleges and universities started in 1980 when the central government enacted the first syllabus-- English Teaching Syllabus by stipulating that English should be taught in all science and technology universities and focused on grammar teaching. In the 1985's and 1986's revised edition, English reading was emphasized and college English test (National College English Test, abbreviated as CET_-band 4) was conducted in 1987 for the first time as the first nationwide test of English. College English Teaching Program in 1999 emphasized ability in speaking and listening. Later, with the development of China's involvement in global economy, College English Curriculum Requirements (2004) focused on practical and comprehensive abilities especially listening and speaking skills. Today, almost every college and university (4 years and 3 years) offer college English course (compulsory course) as the basis of academic reading at the first two years and then specialty-oriented or business-oriented English (academically related to students' major in different departments and schools) at the third and fourth year, while offering various English electives at the same time. Today there are approximately 30 million college students in China studying English as a foreign language and 300 million English learners all together including primary and secondary students (http://www.sundxs.com/baike/12795.html [2020-5-27]).

Though Chinese government stipulated that students should start classroom English study nationwide in the third year of primary school from the September semester of 2001 according to the guidelines and standards set by the Education Ministry of PRC: The Guidelines of Chinese Ministry of Education on Promoting Chinese primary School English Curriculum Reform (2001) and The New Standard of English Curriculum for Chinese Primary Schools and Junior/senior Middle Schools----Experimental Version Drafted by the Education Ministry of the PRC (2011) (http://www.moe. gov.cn), almost all first graders in big cities like Beijing, Shanghai and Guangzhou started English study and most kids even started English study in kindergartens. English cram schools have been prevalent everywhere from big cities to small towns across every corner of China.

\section{Literature Review}

Just as mentioned above, studies of demotivation derived its origin from motivation research in the United States and UK. Both researchers and teachers have been exploring measures to help improve learner's motivation and reduce their demotivation and thus enhance efficiency of language study. This paper also holds the same purpose by trying to avoid the demotivating downsides and enhance English study. Quite a lot of qualitative studies were firstly conducted to both middle school students and college and university students $[3,6$,
$12-15,17,18,23-25]$ about their motivation and demotivation, and later a few quantitative studies were conducted to middle school students.

Gorham and Christophel [16] conducted open-ended questions to all the 308 college students from the first year to the fourth year with the focus of teacher behavior in Introductory Communication Course and the purpose was to improve classroom lecture. They got 2404 responses which were categorized into three demotivating factors: a) factors related to teacher behaviour (issues like not knowledgeable, not in control of classroom, low credibility, lack sense of humour); b) factors with structure/format (including negative physical classroom atmosphere, negative general organization of material, dissatisfaction with grades and assignments), c) factors with context (factors that are out of control of teachers, such as dislike subject area, boring and difficult subject, personal laziness and poor health). Their findings implied that elements central to motivation may significantly differ from those central to demotivation. Motivation was considered to be a student-owned state while demotivation a teacher-owned problem (they conformed the same opinion in their latter study $[17,18])$. And teacher's behavior, just as they hypothesized, was perceived as a salient factor in demotivating students. Their result showed that context factors accounted for $29 \%$ of student-perceived demotivation, teacher behavior factors $34 \%$ and structure/format factors $37 \%$ (they consider the latter two were teacher-related factors and accounted for $71 \%$ of the sources of demotivation).

Chambers [21] administered a questionnaire to 7 teachers and 191 ninth graders enrolled in four schools in Leeds, UK. According to the results of teacher questionnaires, the main characteristics of the demotivated pupils were those who: a) made no effort to learn; showed no interest; demonstrated poor concentration; produced little or no homework; failed to bring materials; b) lacked a belief in their own capabilities; c) demonstrated lethargy and gave negative or nil response to praise; d) were unwilling to cooperate. In brief, teachers perceived a variety of reasons leading to demotivation: psychological, attitudinal, social, historical, geographical factors. On the other hand, the students gave different responses such as that the group was too big; the language room was too small. As to teacher's behaviour, some thought teachers: a) gave long and boring lessons, b) did not give clear enough instructions, c) used inferior equipment, d) did not give sufficient explanations, e) criticized students and f) used old-fashioned teaching materials. He suggested that we should adjust the attitude of parents, friends and society. This study was of significance in that it conducted a survey from both teachers' perspective and student's perspective and that social context was included in the scope.

Oxford [24] analyzed essays written by 250 American students in high schools and universities about their past five years' language learning experiences. After analyzing students' essays, four demotivators came out: a) teacher's personal relationship with students; b) teacher's attitude towards the course or the material; c) style conflicts between teachers and students; d) characteristics of the classroom activities. 
At the same time, a study in Hungary got a different answer. These factors have become a cornerstone study of many other studies on demotivation in studying foreign languages because of Dornyei's continuous study and prestige in this field [5]. He conducted structured interviews with 50 secondary school students in Hungary who were studying either English or German as a foreign language. Nine demotivating factors were identified in order of frequency: a) teachers' personalities, commitments, competence, teaching methods, b) inadequate school facilities (e.g. very large classes, not the right level, or frequent change of teachers), c) reduced self-confidence due to their experience of failure or success, d) negative attitude toward the foreign language studied, e) compulsory nature of the foreign language study, f) interference of another foreign language that pupils were studying, g) negative attitude toward the community of the foreign language spoken, h) attitudes of group members, i) coursebooks.

Japanese scholars did remarkably a lot of studies on demotivation [3, 9, 11, 19, 23], for students in their country were studying English as a second/foreign language and facing quite an exam hell [9].

Aria [3] asked 33 Japanese students who were mostly highly proficient English majors, and got four constructs: a) teachers-related factors (account for $46.7 \%$ of the responses), b) boring and monotonous classes $(36.2 \%)$, c) class atmosphere (13.3\%), and d) other (3.8\%).

Kojima (2004, cited from [11]) surveyed 2198 senior high school students (boy's school, girl's school and coeducation school) with a structural equation modeling by two consecutive surveys. By borrowing Dornyei's model, he got five constructs: a) the language-level factor (outside of the class), b) the learner-level factor, c) the learning situation level factor (within classroom context), d) the student's listening problem, e) the problem of amount of homework. The learner level problem was the biggest demotivator, then the language level problem, and finally the learning situation level problem. Interestingly, English listening and homework burden were specifically pointed out as demotivators.

After following Dornyei's model and conducting interview and a questionnaire in Japanese high school English classrooms, another survey did the same thing and five factors were found through qualitative analysis $[11,19]$ : a) teacher's behavior in classroom, b) the grammar-translation method, c) tests and university entrance examinations, d) the memorization nature of vocabulary learning, e) textbook/reference book-related issues. Similarly, they administered the same 35-item questionnaire to college students firstly and then high school students in Japan in two separate studies. 5 factors were extracted in the first study: a) course books, b) non-communicative methods, c) test scores, d) inadequate school facilities, e) teachers' competence and teaching styles. Their finding was that factors of course books and non-communicative methods were more demotivating than the other three factors. While after that, almost the same questionnaire was conducted to high school students, they got another set of 5 factors: a) learning contents and materials, b) teacher's competence and teaching styles, c) inadequate school facilities, d) lack of intrinsic motivation, e) test scores. Factors a, d and e were demotivating factors for demotivated high school students. These two comparative studies proved seemingly that there was a difference between the demotivating factors of university students and middle school students. As a matter of fact, all the three researches got factors that were overlapped with each other by including teacher-related, test-related, teaching material-related and facility-related factors in all the studies.

Falout et al. [4] investigated 900 university students by using 52-item questionnaire and got 6 factors: a) teacher immediacy, b) grammer-translation method, c) course book, d) self-denigration, e) value, f) self-confidence. They suggested that teachers should try avoiding monotonous teaching and employ a combination of various teaching methods. Learning outcomes can be improved by maintaining students' confidence and developing their adaptive autonomy skills.

Kim [20] studied Korean's elementary school students' decreased motivation through a 12-item questionnaire. Pupils in elementary schools who often attended private institutes after school-time often were more demotivating than those who did not. School grade and prior experiences in private institutes were the most demotivating factors. There was a statistically significant and consistent decrease in students' satisfaction with: a) their learning experience, b) ultimate success in English, c) intrinsic and extrinsic motivation, d) integrative/instrumental motivation.

Quiet recently, a few quantitative studies were conducted in China. On 277 non-English major freshmen and sophomore students in a local provincial university of south China, Tang [13] got 10 factors including English language level problem, teaching content, teacher's characteristics, teacher's teaching abilities and methods, teaching model, homework and assignment, teaching facilities, graded class $\mathrm{A} / \mathrm{B}$, unstable motivation, studying atmosphere, negative influence of other subjects and after-class activities.

Another study was based on the findings taken from 766 university EFL learners (a key university in a well-developed province in the east part of China) in a 40-item questionnaire survey, Zhou and Wang [14] investigated learners' demotivating behaviors and their correlated factors and extracted five demotivators in 2 categories: a) external factors (teachers' competence and teaching styles, curriculum and materials, and inadequate facilities), b) internal factors (lack of intrinsic interest, learning strategies deficiency). They claimed that external factors have more influence than internal counterparts. Teachers' competence and teaching styles as well as learning strategies deficiency turned out to be the most influential in demotivating students in their university.

Based on a Beijing municipal university, Xie [15] conducted a quantitative study on demotivators of 331 freshmen of different majors in a finance-oriented university in a very big city and got 7 factors: a) teacher's competence and teaching style, b) amount of English words and complexity of grammar, c) teaching material and assessment, d) career planning, e) after-class self-study, f) physical 
environment of classroom, g) the lengthy and dull content of teaching material. The suggestion was that teachers should improve their teaching competency and paid more attention on practical usage of English.

In almost every study of demotivation, teacher-related factor was always playing a role in demotivating students [3-5, 11-19, 21, 24]. According to Zhang [12] who investigated teacher misbehaviors in the U.S., China, Germany, and Japan, he reported his findings by stating that: a) teachers across cultures all were perceived to misbehave infrequently, with only slight variations found across cultures, b) teachers across cultures were perceived to engage in similar misbehavior tendencies, c) teacher misbehaviors were associated with learning demotivators across cultures and within each culture, but they differed in the magnitude as predictors, explaining $8 \%-39 \%$ of the variance in student demotivation across cultures. Overall, incompetence was the most common form of teacher misbehaviors, and some of the most frequently reported teacher misbehaviors were similar across cultures. The implied meaning of Zhang's study showed that, despite teachers' efforts in preparing classes, delivering lectures and creating a positive learning atmosphere, students still thought teacher's misbehavior was one of the most demotivating origins of their status. Whatsmore, teacher's incompetence, offensiveness, and indolence all belong to teacher misbehaviors.

From all the factors mentioned above, we hypothesized demotivators in five levels: the language level (vocabulary and grammar rules, etc.), the learner level (personal qualities and interest, confidence, etc.), the teacher's level (incompetence, teaching style etc.), school facility level (class size, physical environments of the classroom, frequent change of teacher, etc.), learning situation level (classroom atmosphere, peer's or parents' view) and social context (the view of a language from the point view of the whole society etc.). This study conducted a questionnaire based on the five constructs and on my more than twenty years of English teaching experience in a municipal-level university where a lot of students especially the struggling students frequently complained about difficulties in English words memorization and complicated grammar rules. It investigated the present situation of demotivation in Chinese university students.

Issues of vocabulary and grammar are prominent in Chinese context which is quite different from Dornyei's research where grammar and vocabulary were not mentioned as demotivating factors. While Arabic learners of English in Israel junior and senior high schools, Korean and Japanese students [4, 11, 19, 20] have gone through the same grammer-related difficulties. Problems of grammar and words are sometimes considered the most demotivating factor in some study [20]. The questionnaire used in this study offered items about vocabulary and grammar. But here across China until now, there was still little quantitative study about the present situation of demotivators in university students. So, based on previous study, this paper has the following two research questions:

1. What are the demotivators that hinder the motivation of university students in municipal universities in China?

2. How Chinese university students' demotivators overlap those of other countries?

\section{Method}

\subsection{Participants}

605 university students participated in the survey and 600 questionnaires were collected, and 588 questionnaires were confirmed to standard, so the affective number of the questionnaires was $588(\mathrm{n}=588)$. There are 456 female students and 132 male students (with the percentage of $77.6 \%$ and $22.4 \%$ respectively) with an average English studying year of 11.16 (with 12 years as a mode). The range of age is 17 to 24 years old and average age is 19.28 with 19 years old as the mode. There are 253 freshmen (43\%), 222 sophomores (37.8\%), 90 junior students $(15.3 \%)$ and 23 senior college students (3.9\%) all together. 133 students from English major who specialize in Business-English-oriented courses while the other 455 pupils from non-English majors like economics, human resources, logistics, and law who study College English course for non-English majors, which is prevalent in China. According to the final score of the College Entrance Exam (Gaokao), 72 people got a score of less than 90 out of 150 points, 103 students with the score range of 91-100, 130 students within the range of 101-110, 106 students within the range of 111-120, 23 most advanced students belong to the top group with a score over 120 out of a 150 points full mark. There are all together 150 students who did not offer their college entrance test score. In order to compare the demotivated group and the motivated group, the first $1 / 3$ and the last $1 / 3$ of the total score of the survey were defined as the demotivated group and the motivated group.

\subsection{Questionnaire Design}

Based on previous study of researchers $[6,11,16,26]$, the present questionnaire consisted of two sections: the first section consisted of 35 5-point Likert type questions about demotivation (see appendix) covering teacher aspect, teaching content and material, teaching facilities, coursebooks related problems, languages itself, social context, others' influence and career planning which were manifested in pretest and pre-interview. 4 items about the demotivation status were included at the end of the first section. The second section was a demographic section which collected information about grade, age, gender, major, college entrance score and years of English study.

The questionnaire included 4 items about motivation status: time of after-class study, amount and extra reading after school, degree of concentration in classroom lecture, and degree of commitment in after-class/school assignments. Participants were required to choose one from five options (see appendix). Based on the response to this question, the participants were divided into 3 categories: demotivated learners, medium level students and motivated learners. This study mainly compared the first $1 / 3$ and the latter $1 / 3$ students. 
In most previous research studies, category of student level was based on either proficiency level resulted from a language proficiency test [4] or self-reported status of motivation [11]. In this survey, four items were designed to decide whether the students were motivated or demotivated because we think it is not reliable and persuasive to do research on the sole basis of self-reporting. It is understandable that low proficiency group is not necessarily demotivated student, for, in my own teaching experience, I can see frequently the highly motivated students got a low mark in the test result while most researchers was seemingly considering the equal relationship of high proficiency student with motivated students. People who didn't think highly of English in their schedule may get a good result in the proficiency test, but in fact he was not so motivated to study a foreign language as others do. That is to say, an individual is not as interested in a foreign language study as before though he could definitely be. In the preliminary study, we found some self-reported demotivated students were in the eyes of their teacher motivated ones. Besides, even different teachers and researchers have slightly different opinions on motivated students and demotivated students, let alone students themselves. As to language learners, they are not $100 \%$ definitely sure of their own motivation status in academic terms of motivation and demotivation. Besides, demotivation is such a new term that we are not sure all the participants gain a unanimous agreement on it. So, 4 items were designed.

\subsection{Analysis}

The questionnaire went firstly through a reliability test by using SPSS 17.0. The reliability coefficient of the 35 items in the whole questionnaire estimated by Cronbach's alpha is
0.908 which shows the survey was consistently designed and very acceptable under the same construct. To explore the factor structure of the questionnaire items, an exploratory factor analysis was performed. The inter-reliability of each factor was also conducted and was reliable in each factor.

\section{Results}

Seven demotivators were extracted from the survey. Table 1 is the descriptive statistics of all the 35 items. The average of most of the items were below 3 , and the means of 8 dominant items among the 35 items are above 3 which shows that students consider the eight items the most demotivating items, to be specific, they are: item 2 (laziness) $=3.68$, item 5 (testing method $)=3.38$, item 8 (test orientation of the course $)=3.18$, item 32 (difficulties with vocabulary and Grammer) $=3.16$, item 11 (lack of communicative ability) $=3.13$, item 41 (no development of communication in English $=3.12$, item 30 (don't know how to study well) $=3.10$ and item 7 (poor listening $)=3.04$. It is quite noticeable that personal laziness is the most demotivating item. The second biggest barrier to study English was related with endless tests which was oriented for college entrance, this similarly happened in Japan as middle school English was an exam hell [4]. According to the pre-interview, learners complained huge number of tests, and English study was typically exam-oriented in typical classroom lecture. In the present educational system, grade is too often the only way to value proficiency of a learner, which would very much decide many other aspects such as opportunities and scholarship in school. The third biggest barrier is English language itself as it has too many words, grammer rules to follow in the process of study.

Table 1. Descriptive Statistics for university Students' Questionnaire (N=588).

\begin{tabular}{|c|c|c|c|c|c|c|c|}
\hline & Mean & SD & Variance & Skewness & & Kurtosis & \\
\hline & Statistic & Statistic & Statistic & Statistic & Std. error & Statistic & Std. error \\
\hline 2laziness & 3.68 & 1.028 & 1.056 & -.652 & .101 & -.083 & .201 \\
\hline 5testingmethod & 3.38 & 1.119 & 1.252 & -.187 & .101 & -.721 & .201 \\
\hline 8testorientization & 3.18 & 1.166 & 1.359 & -.018 & .101 & -.986 & .201 \\
\hline 32vocabularyandgrammer & 3.16 & 1.206 & 1.454 & -.103 & .101 & -.897 & .201 \\
\hline 11communicativeability & 3.13 & 1.211 & 1.465 & .080 & .101 & -1.046 & .201 \\
\hline 41 communication & 3.12 & 1.322 & 1.747 & -.100 & .101 & -1.153 & .201 \\
\hline 30noknowhow & 3.10 & 1.146 & 1.312 & -.003 & .101 & -.773 & .201 \\
\hline 7poorlistening & 3.04 & 1.179 & 1.390 & .149 & .101 & -.917 & .201 \\
\hline 10unpracticalcontent & 2.98 & 1.123 & 1.262 & .297 & .101 & -.805 & .201 \\
\hline 4anxiety & 2.93 & 1.189 & 1.415 & .098 & .101 & -.965 & .201 \\
\hline 44noconfidence & 2.86 & 1.207 & 1.457 & .090 & .101 & -.816 & .201 \\
\hline 29learningstrategy & 2.83 & 1.103 & 1.216 & .203 & .101 & -.602 & .201 \\
\hline 12teachingspeed & 2.82 & 1.017 & 1.034 & .396 & .101 & -.390 & .201 \\
\hline 27careerplan & 2.80 & 1.237 & 1.530 & .198 & .101 & -.977 & .201 \\
\hline 15boringtext & 2.78 & 1.141 & 1.302 & .282 & .101 & -.712 & .201 \\
\hline 14longtext & 2.77 & 1.061 & 1.126 & .247 & .101 & -.628 & .201 \\
\hline 43 grammerfocus & 2.72 & .991 & .982 & .375 & .101 & -.044 & .201 \\
\hline 42grammer-translation & 2.67 & 1.084 & 1.174 & .378 & .101 & -.304 & .201 \\
\hline 19classroomcontext & 2.67 & 1.154 & 1.331 & .327 & .101 & -.729 & .201 \\
\hline 26lostinterest & 2.62 & 1.216 & 1.479 & .381 & .101 & -.782 & .201 \\
\hline 9unfairgrading & 2.61 & .977 & .955 & .527 & .101 & -.085 & .201 \\
\hline 20 friends & 2.59 & 1.105 & 1.221 & .323 & .101 & -.624 & .201 \\
\hline 25nopurpose & 2.51 & 1.159 & 1.344 & .509 & .101 & -.529 & .201 \\
\hline 22teacherpraise & 2.39 & .948 & .899 & .554 & .101 & .178 & .201 \\
\hline 21disadvantagedcomparison & 2.29 & 1.054 & 1.112 & .795 & .101 & .147 & .201 \\
\hline
\end{tabular}




\begin{tabular}{llllllll}
\hline & Mean & SD & Variance & Skewness & \multicolumn{2}{c}{ Kurtosis } \\
\hline & Statistic & Statistic & Statistic & Statistic & Std. error & Statistic & Std. error \\
\hline 38humor & 2.24 & 1.086 & 1.179 & .723 & .101 &. .104 & .201 \\
24pressureofparents & 2.21 & 1.075 & 1.156 & .891 & .101 & .293 & .201 \\
18classsize & 2.20 & 1.040 & 1.082 & .901 & .101 & .371 & .201 \\
39monotonousteaching & 2.17 & 1.089 & 1.186 & .866 & .101 & .186 & .201 \\
13hwcheck & 2.17 & .894 & .800 & .946 & .101 & 1.080 & .201 \\
37nofocus & 2.09 & 1.027 & 1.055 & .819 & .101 & .021 & .201 \\
33tchrpatience & 2.02 & .982 & .964 & .963 & .101 & .587 & .201 \\
40jeer & 1.99 & 1.149 & 1.320 & 1.078 & .101 & .257 & .201 \\
36classpreparation & 1.97 & .979 & .958 & 1.057 & .101 & .844 & .201 \\
35pronunciation & 1.96 & .954 & .910 & 1.024 & .101 & .900 & .201 \\
16poorrelationship & 1.95 & 1.007 & 1.013 & 1.001 & .101 & .375 & .201 \\
Valid N (listwise) & & & & & & & \\
\hline
\end{tabular}

In order to extract students' demotivators of foreign language study, a principal axis factor analysis was performed on the 35 items. Based on the interpretability of the factor solution, a 7-factor solution was drawn by using SPSS17.0. Seven factors were rotated (see table 2). The cumulative loading of all the items is $56.665 \%$.

The first factor included 7 items with factors loading above. 612. The items concerned teacher's class activity preparation, such as not focused in explanations of knowledge points, poor pronunciation, lack of humor, impatience, boring teaching method, and even jeers or criticisms from teachers. So the first factor ( 7 items) was named teacher-related competence factor because teaching method, humorous explanation of a lecture, teachers' patience, lecturing focus and logic were achieved through teacher's teaching competence. Interestingly, humorous language of classroom lecture in almost every study was considered one of the most important demanding teaching abilities of a teacher. Generally, teacher's pronunciation and fluency would bring direct impact on a student, preparation of a lecture would influence the efficiency of knowledge transmission, and too much teacher's assignment would burden students a lot.
The second factor can be named the learner level factor. 9 items including personal laziness (so many words and Grammer rules to follow), anxiety, confidence, interest, lack of learning strategy and poor listening all lead to demotivation. When there are too many words to remember and too many complicated grammar rules to recite (which is a popular opinion of most teachers and parents especially in newly developed economically wealthy families in big cities like Beijing and Shanghai, and where lots of families would spoil their children a lot just for the sake of parents' regrets). And these definitely will increase their anxiety without using good learning strategy. That is the reason why the second factor can be named as the learner-level factor.

The third factor was defined by 5 items related to teaching content and material. Unpractical content in the textbook taught for test-orientation with no emphasis on developing students' practical ability such as communicative ability made the teaching material and teaching content quite boring, especially for some long texts which disinterest learners' patience and endurance, according to some demotivated students. Teaching material was not reality-based, only catering to exam.

Table 2. Factor analysis of demotivation (35 items).

\begin{tabular}{|c|c|c|c|c|c|c|c|}
\hline \multicolumn{8}{|c|}{ Rotated Component Matrix ${ }^{a}$} \\
\hline \multirow{2}{*}{ No. and items } & \multicolumn{7}{|l|}{ Component } \\
\hline & $1(\alpha=.906)$ & $2(\alpha=.829)$ & $3(\alpha=.743)$ & $4(\alpha=.763)$ & $5(\alpha=.650)$ & $6(\alpha=.589)$ & $7(\alpha=.624)$ \\
\hline 37nofocus & .830 & & & & & & \\
\hline 35pronunciation & .808 & & & & & & \\
\hline 38humor & .766 & & & & & & \\
\hline 33tchrpatience & .738 & & & & & & \\
\hline 39monotonousteaching & .709 & & & & & & \\
\hline 40teacher'sjeer & .612 & & & & & & \\
\hline 30noknowhow & & .809 & & & & & \\
\hline 29learningstrategy & & .673 & & & & & \\
\hline 32vocabularyandgrammer & & .635 & & & & & \\
\hline 2laziness & & .625 & & & & & \\
\hline 7poorlistening & & .593 & & & & & \\
\hline 26lostinterest & & .585 & & & & & \\
\hline 27 careerplan & & .544 & & & & & \\
\hline 44noconfidence & & .488 & & & & & \\
\hline 11 communicativeability & & & .719 & & & & \\
\hline
\end{tabular}




\begin{tabular}{|c|c|c|c|c|c|c|c|}
\hline \multicolumn{8}{|c|}{ Rotated Component Matrix ${ }^{a}$} \\
\hline \multirow{2}{*}{ No. and items } & \multicolumn{7}{|l|}{ Component } \\
\hline & $1(\alpha=.906)$ & $2(\alpha=.829)$ & $3(\alpha=.743)$ & $4(\alpha=.763)$ & $5(\alpha=.650)$ & $6(\alpha=.589)$ & $7(\alpha=.624)$ \\
\hline 10unpracticalcontent & & & .704 & & & & \\
\hline 15boringtext & & & .634 & & & & \\
\hline 12teachingspeed & & & .580 & & & & \\
\hline 14longtext & & & .463 & & & & \\
\hline 19classroomcontext & & & & .725 & & & \\
\hline 20 friends & & & & .701 & & & \\
\hline 18classsize & & & & .578 & & & \\
\hline 21 disad. comparison & & & & .563 & & & \\
\hline 22teacherpraise & & & & .432 & & & \\
\hline 42grammer-translation & & & & & .759 & & \\
\hline 43grammerfocus & & & & & .757 & & \\
\hline 41communication & & & & & .526 & & \\
\hline 24pressureofparents & & & & & & .563 & \\
\hline 25nopurpose & & & & & & .547 & \\
\hline 16poorrelationship & & & & & & .513 & \\
\hline 5testingmethod & & & & & & & .660 \\
\hline 8testorientization & & & & & & & .565 \\
\hline 9unfairgrading & & & & & & & .544 \\
\hline
\end{tabular}

Extraction Method: Principal Component Analysis.

Rotation Method: Varimax with Kaiser Normalization.

a. Rotation converged in 8 iterations.

The fourth factor drawn from the 5 items can be classified into inadequate school facilities and judgements including not so good classroom atmosphere, inappropriate or even big class size, detrimental comparison between students by both parents and teachers, even with the teacher's weak praise. All these will bring a negative influence to learners.

The fifth factor can be attributed to the much-accused way of grammar-translation teaching method. Too much grammar rules and lack of real and effective communication lead to the dullness of language learning. Besides grammar and words, students could not see the practicality and benefits or enjoyment from learning a foreign language. In most students' logic, they couldn't recognize their practicability of English study and English was always seemed useless for them in their life besides exams and tests especially in the period of middle school.

The sixth demotivator is closely related to the fifth one and it is about lack of purpose in second or foreign language learning. Students hold the opinion that they did not learn for themselves but for their parents. This factor is closely connected to China's present situation where parents think more highly of a foreign language while not all the young generation would bear the same opinion as their parents. It is common in a Chinese family when parents face the career barrier of language in their career development, they would wish their children overcome the shortcoming and emphasize a lot of importance of English as a foreign language to their children. That is why there are so many after-class institutions with New Oriental Education \& Technology Group (www.neworiental.org) as the most famous one in China. Most parents in big cities would pay for their children to study a foreign language, usually English. Plus, people of the parent age who developed well in their career often use or speak a foreign language in their job. Besides, the development of the global market involves China more than before and parent would think English will play a key role in the future career. Thus, most parents would require their children to master a foreign language and English would be the first option for many families.

The seventh factor is related to test pressure. Test-oriented study and simple or even unfair grading system may demotivate learner from continuous study and lag behind others. Students are facing too many tests and the grades of the tests are not as satisfying under the pressure of college entrance exam which is really a tough one for all students who would go to universities on the basis of their score in a developing country like China. Students would choose universities mainly on the basis of the fame of the university for the sake of a bright future which is measured mainly by the amount of money they would make after graduation instead of on their own interest. A high score often means too many things for a student's future (even a whole life in the eyes' of some parents).

Table 2 also shows the reliability coefficients of each factor as estimated by Cronbach's alpha. All the 7 factors have relatively high reliability coefficients.

After the independent samples t-test analysis, the mean score of every factor differs, see table 3. Though teacher-related teaching competence is the first factor, the mean score is relatively low $(\mathrm{M}=2.04)$, while test pressure (factor 7) and personal-related characteristics (factor 2) are more demotivating than other factors $(\mathrm{M}=3.07, \mathrm{M}=3.00)$. The possible underlying reason may be that university teachers are trying to regulate their behaviors and 
improving their teaching competence all the time with the development of education and the training program given by education ministry and other departments. Among the seven factors, there is no significant difference between the demotivated group and motivated group. The two groups are homogeneous in demotivators which may implies that all the students are coming from the less motivated group for the facts that participants in this university are academically falling behind the students of top key universities in China.

Table 3. Descriptive Statistics of each factor for demotivated group and motivated group.

\begin{tabular}{ll}
\hline Factor & mean \\
\hline 1. teacher-related competence factor $(\mathrm{k}=7)$ & 1.91 \\
demotivated learners $(\mathrm{n}=196)$ & 2.16 \\
motivated learners $(\mathrm{n}=211)$ & 2.04 \\
Total $(\mathrm{n}=407)$ & \\
2. learner-level factor $(\mathrm{k}=9)$ & 2.64 \\
demotivated learners $(\mathrm{n}=196)$ & 3.32 \\
motivated learners $(\mathrm{n}=211)$ & 3.00 \\
Total $(\mathrm{n}=407)$ & \\
3. teaching content and material $(\mathrm{k}=5)$ & 2.79 \\
demotivated learners $(\mathrm{n}=196)$ & 3.02 \\
motivated learners $(\mathrm{n}=211)$ & 2.91 \\
Total $(\mathrm{n}=407)$ & \\
4. inadequate school facilities $(\mathrm{k}=5)$ & 2.10 \\
demotivated learners $(\mathrm{n}=196)$ & 2.62 \\
motivated learners $(\mathrm{n}=211)$ & 2.42 \\
Total $(\mathrm{n}=407)$ & \\
5. grammar-translation teaching method $(\mathrm{k}=3)$ & 2.66 \\
demotivated learners $(\mathrm{n}=196)$ & 2.99 \\
motivated learners $(\mathrm{n}=211)$ & 2.09 \\
Total $(\mathrm{n}=407)$ & \\
6. lack of purpose in foreign language learning $(\mathrm{k}=3)$ & \\
demotivated learners $(\mathrm{n}=196)$ & 2.90 \\
motivated learners $(\mathrm{n}=211)$ & \\
Total $(\mathrm{n}=407)$ & \\
7. test pressure $(\mathrm{k}=3)$ & \\
demotivated learners $(\mathrm{n}=196)$ & \\
motivated learners $(\mathrm{n}=211)$ & \\
Total $(\mathrm{n}=407)$ & \\
\hline & \\
\hline
\end{tabular}

\section{Discussion}

The first research question asked about the demotivating factors for college students. The extracted 7 factors were as follows: teacher-related competence factor, learner-level factor, teaching content and material, inadequate school facilities and unfair judgement, grammar-translation teaching method, lack of purpose in foreign language learning, and test pressure.

The second research question how Chinese local college students' demotivators overlap these of foreign students' demotivators. Quite interesting results come after 7 factors were extracted. And most of these factors are widely prevalent around the world. There are too many similarities and minor differences exists which are considered essential in a Chinese context.

Firstly, the similarities are that there exist teacher-related and learner-related factors that demotivate students. Factors such as teacher's competence, humor and preparation, teacher's behaviour always are factors as often mentioned as in many other studies before [3,7]. They are still the most influential demotivators that teachers should try to avoid in their teaching. As to the student-related problems, they would contribute their demotivation to personal status such as laziness, anxiety, losing confidence because of previous grades, inappropriate learning methods, too many tests. Instead of unilaterally blaming teachers for demotivation, they also found faults with themselves. The reason was that Chinese culture is different from western culture which is inwardly developed, and which encourages finding faults with themselves. The other possible reason is that during the process, teachers and parents tend to imply directly and indirectly that they should work hard themselves without blaming others for that the purpose of studying is for themselves instead of studying for others. As to other factors like teaching content and material problem, grammar translation problem, inadequate school facilities problems, testing pressure and grading system are often found in other countries such as in Korea and Japan [3-5, 11-19, 21, 24].

The differences, if any, lie in the learner-level factors with laziness which demonstrates significance among the demotivators. Students in this school, on the one hand, did not go to a very top school not because of their intelligence, but because of their misbehavior, to be specific, because of their laziness, in other words, they lack of self-disciplined study habit, and thus lack of confidence. Some students confessed in the pre-interview that they were not working as hard as the other students who entered a better school (there are more than 100 key universities in the catalog of 211 universities and 985 universities in China). Participants in this university performed not as well as key university students for they did not work as hard as others, so they came to a local college. Secondly, their self-control ability was not considered as good as the others when they told the researcher that they often could not control themselves in things like playing games and idling around. When talking with parents of the middle school students, the researcher found that some parents prefer to view their children as kind of laziness, not working hard. On the other hand, when interviewing teachers, they very often ask students to rotate words even grammer rules after class, while students are not interested in it. Teachers would label students as being lazy, uncooperative and inactive in English study.

Quite uniquely and not quite understandable to westerner was the sixth factor: purpose of language study which was quite different and seldom mentioned in other studies. From my point of view, this is closely related to traditional Chinese culture where parents often think highly the importance of foreign language study and parents often missed the opportunity of studying a foreign language and would frequently put their own wishes into their children's own future life. Too many children and students were complaining about bearing their parents dream in their study, which is a 
common phenomenon in China. In the eyes of parents, a foreign language often meant a higher social status and a quick emerge into the world.

As to the purpose of second language learning, other perspectives for promoting the motivation or remotivate students in foreign language study are urgently needed. For example, Investment Theory [27] considered the effort in language as investment where a learner can decide how much effort, energy and time etc. should be spent on study a language. On the other hand, an ideal self may be beneficial in building the internal locus of language study in the framework of L2 Motivational Self System [28] which thinks an ideal L2 self is essential in personal growth and development. If a foreign language competency is embedded in a future ideal self, the remotivation may be possible and practical.

\section{Conclusion}

The 7 factors showed that teacher-related factor and learner-level factor were the biggest demotivators for quite a lot of Chinese university students. And teachers' teaching abilities and behaviour was the second barrier. The results in this study are basically in line with other studies abroad and fall into the original hypothesis.

Based on the findings of this study, the following advice should be proposed to any context that is similar to this one.

1. Teacher's teaching competence should firstly be enhanced with the development of modern science and technology. Be it in secondary school or high school, constant teaching capability improvement is the eternal target of educational experience. Teachers should avoid the loopholes of these demotivators.

2. Students should be encouraged to overcome personal shortcomings such as laziness and bias against language in their future career plan and establish a clear goal. With the development of China's economy and globalization, English would be more and more important in career planning and personal development. Teachers and society should work on motivating the learners and building students confidence.

3. Poor test results were very demotivating to demotivators. Teachers and parents should encourage students more in improving their grades by hardworking. Dornyei (2001b) suggested giving some encouragement for tests may be necessary.

However, there are a lot of limitations of the study. This study can be only a very preliminary study because: Firstly, the type of school was limited to one university, and there are actually different levels of university in China. There should be different contexts happened in different schools. The following future study should cover more schools and should also query high school students attending various types of high schools other than general course. Secondly, the number of participants is limited to 588 students. The future study should consider more students of all grades and different majors in different schools. Thirdly, the questionnaire may have excluded other demotivating factors. We also recommend measuring the level of motivation with an established instrument to find relationship between participants' motivation and their perception of demotivation. Fourthly, the ultimate purpose should be remotivation instead of listing the demotivators only [4], for the real purpose of any research should deal with practical problems in reality. More study about remotivation should be investigated and spread to students to remotivate learners' motivation [15]. We hope more research in this area in the future so that we can deepen the insights about learners' motivation and give more practical implications and suggestions for both teachers and students.

\section{Appendix}

\section{Appendix 1. Questionnaire of Demotivation in College Students (Translated from Chinese)}

The First Section: Questionnaire

1. I was lazy and had no self-discipline.

2. There is something wrong with my learning method.

3. Testing methods are too simple.

4. I was poor in listening.

5. English was test-oriented.

6. Grading standard was unfair and unclear.

7. Teaching content is not practical and useful.

8. Communicative abilities were not cultivated.

9. Classroom teaching pace was too fast.

10. Texts were too long.

11. Texts were not interesting.

12. There was a poor relationship between teacher and students.

13. There was a too big class size.

14. There was no good studying atmosphere in the classroom.

15. My friends didn't like studying English.

16.I was compared to a disadvantaged position by others including teachers, parents, and relatives.

17.I was not praised by teachers. 
18. There was pressure from parents and other people.

19. I did not know the real purpose of studying English.

20.I lost interest in English.

21.I had no career plan related to English in the future.

22.I seldom employ learning strategies like deducting in guessing word meaning, text meaning.

23. I did not know the way of studying English well.

24. There were too many English words and grammar rules.

25. Teachers were impatient to students.

26. Teacher's pronunciation was not standard and hard to understand.

27. Teacher made no preparation for classroom lectures.

28. Teacher did not explain points clearly.

29. Teaching language was not humorous.

30. Teaching method was monotonous.

31.I was laughed by teachers.

32. There was no opportunity to speak English in daily life.

33. Grammer-translation method was used too often.

34. Grammer instruction took too much classroom time.

35. I didn't believe my language ability.

36. Extra study time every week:

1. 1-2 hs. 2. 3-4 hs. 3. 5-6hs. 4. 7-8hs. 5. More than 8 hs.

37. Interests in after-school English study (watching English movies, cartoons, English contests and TV series, enjoy listening to English songs and speeches):

1. No interest at all 2. A little interest 3. Interested 4. quite interest 5. A lot of Interest

38. Intensity in studying in classroom:

1. Not at all 2. A little 3. Medium 4. More than medium 5. Very much

39. Degree of seriousness in finishing after-class homework:

1. Not at all 2. A little 3. Medium 4. More than medium 5. Very much

40. Other issues that I met:

\section{Appendix 2. The Second Section: Demographic Information}

Grade: 1. First year 2. Second year 3. Third year 4. Fourth year

Gender: 1. Male 2. Female

Score of college entrance exam (full score: 150):

Below 90 2. 90-100 3. 101-110 4. 111-120 5. Above 120

Major:_age:__school:___ Years of English study

Score of National College English Test (CET-4)___ CET-6 (if any)

Score of Test of English Major (TEM-4, if any)

\section{References}

[1] Gardner, R. C., \& Lambert, W. (1972). Attitudes and Motivation in Second Language Learning. Rowley, MA: Newbury House.

[2] Ushioda, E. (2013a). Motivation and ELT: global issues and local concerns, In Ema Ushioda (eds.) International Perspectives on Motivation-Language Learning and Professional Challenges, Palgrave Macmillan.

[3] Arai, K. (2004). What 'Demotivates' Language Learners? Qualitative Study on Demotivational Factors and Learners' Reactions. Bulletin of Toyo Gakuen University 12: $39-47$.

[4] Falout, J., Elwood, J., \& Hood, M. (2009). Demotivation: affective states and learning outcomes. System 37: 403-417.

[5] Dornyei, Z. (1998). Demotivation in Foreign Language Learning. TESOL. 1998 Congress, Seattle.

[6] Dornyei, Z. (2001a). Motivational Strategies in the Language Classroom, Cambridge: Cambridge University Press.

[7] Dornyei, Z. (2001b). Teaching and researching motivation. Harlow: Longman.

[8] Ushioda, E. (1998). Effective motivational thinking: A cognitive theoretical approach to the study of language learning motivation [A]. In E. Soler \&V. Espurz (eds.) Current Issues in English Language Methodology. Castelló de la Plana: Publicacions de la Universitat Jaume I: 77-89.

[9] Ushioda, E. (2013b). Foreign language motivation research in Japan: An 'insider' perspective from outside Japan, In Matthew T. Apple, Dexter Da Silva \& Terry Feller (eds.). Language Learning Motivation in Japan: 5.

[10] Kim, T. Y. (2009). The social cultural interface between ideal self and ought-to self: a case study of two Korean ESL students' motivation. In Dornyei, Z., \& Ushioda, E. (eds.), Motivation, Language Identity and the L2 Self. Multilingual Matters 248-273.

[11] Sakai, H., \& Kikuchi, K. (2009). An Analysis of Demotivators in the EFL Classroom. System 37: 57-69. 
[12] Zhang, Q. (2007). Teacher misbehaviors as learning demotivators in college classrooms: A cross-cultural investigation in China, Germany, Japan, and the United States. Communication Education 56/2: 209-227.

[13] Tang, W. L. (2012). Demotivation study among non-English major college students. Foreign Language Education 33/1: 70-75.

[14] Zhou, C. B., \& Wang, W. B. (2012). Demotivators analysis of Chinese university EFL learners. Chinese Foreign Language 9/1: 48-55.

[15] Xie G. M. The study of demotivators on college English in Beijing's higher education]. Journal of Tianjin Foreign Studies University, 2013 (6): 25-29.

[16] Gorham, J. S., \& Christophel, D. M. (1992). Students' perceptions of teacher behaviors as motivating and demotivating Factors in college classes. Communication Quarterly 40 (3): 239-252.

[17] Christophel, D. M., \& Gorham J. A. (1995). Test-retest Analysis of Student Motivation, Teacher Immediacy, and Perceived Sources of Motivation and Demotivation in College Classes. Communication Education 44: 292-306.

[18] Gorham, J. S., \& Millette, D. M. (1997). A comparative analysis of teacher and student perceptions of sources of motivation and demotivation in college classes. Communication Education 46/4: 245-261.

[19] Kikuchi, K. (2009). Listening to our learners' voices: what demotivates Japanese high school students?. Language Teaching Research 13/4: 453-471.
[20] Kim, T. Y. (2011). Korean elementary school students' English learning demotivation: a comparative survey study. Asia Pacific Education Review 12: 1-11.

[21] Chambers, G. (1993). Taking the "de" out of Demotivation. Language Learning Journal 7: 13-16.

[22] Aladdin, A. (2012). Demotivating factors in the Arabic language classroom: What demotivates non-Muslim Malaysian learners when it comes to learning Arabic? 3rd World Conference on Learning, Teaching and Educational Leadership (WCLTA-2012).

[23] Hasegawa, A. (2004). Student demotivation in the foreign language classroom. Takushoku Language Studies, 107: 119-136.

[24] Oxford, R. L. (1998). The unraveling tapestry: teacher and course characteristics associated with demotivation in the language classroom. Demotivation in Foreign Language Learning TESOL. 98 Congress 1 Seattle.

[25] Falout, J., \& Maruyama, M. (2004). A comparative study of proficiency and learner demotivation. The Language Teacher 28: 3-9.

[26] Gao Y. H., Zhao Y., Cheng Y., \& Zhou Y., (2003). Motivation types of Chinese college undergraduates (in Chinese). Modern Foreign Languages, 26 (1): 28-38.

[27] Pittaway, D. S. (2004). Investment and second language acquisition. Critical Inquiry in Language Studies 1: 203-218.

[28] Dörnyei, Z. (2009). The L2 motivational self-system. In Dornyei, Z., \& Ushioda, E. (eds.) Motivation, Language Identity and the L2 Self. Multilingual Matters, 2009: 9-42. 